\title{
THE RELATIONSHIP BETWEEN PLANT DIVERSITY AND PRODUCTIVITY IN NATURAL AND IN MANAGED GRASSLANDS
}

\author{
ASSAF, T.A. ${ }^{1}{ }^{*}-$ BEYSCHLAG, ${ }^{2}{ }^{2}-$ ISSELSTEIN, J. $^{1}$ \\ ${ }^{1}$ Department of Crop Sciences, Grassland Science, Georg August University, \\ von Siebold Strasse 8, D-37075, Goettingen, Germany \\ (phone: +49(0)551 395763; fax: +49(0)551 399355) \\ ${ }^{2}$ Department of Experimental and Systems Ecology, Bielefeld University, \\ Universitatsstrasse 25, D-33615 Bielefeld, Germany \\ *Corresponding author \\ e-mail:tassaf@gwdg.de
}

(Received 29 $9^{\text {th }}$ October 2010; accepted $14^{\text {th }}$ March 2011)

\begin{abstract}
Despite the fact that several experiments have been conducted to explore the biodiversityproductivity relationship in synthesized and natural plant communities, the results obtained were contradictory and no clear consensus has been reached. Recent experiments that surveyed mature natural plant communities have investigated this relationship across environmental gradients, where biotic and/or abiotic factors are correlated with the observed diversity and productivity levels. We studied the effect of plant diversity on ecosystem productivity in agriculturally managed (managed at a low intensity with moderate level of disturbance) and natural (no history of management) grasslands at a within-site scale in order to minimize the confounding effect of environmental factors. We tested the effects of two diversity measures (species richness and species evenness) on productivity within- and across-sites scale. Our results indicated that this relationship was different between the natural and the managed grasslands and varied according to the diversity measure. Species richness only poorly explained the variation in productivity for the managed grasslands, while the variations in system productivity were better explained by species evenness. Interestingly, our results from the natural low productive, species poor grassland are in agreement with the results obtained from the recent experiments that artificially manipulated diversity levels and found an asymptotic increase in productivity along with increasing species richness. Our results provide additional evidence of the complex behavior that measures of species diversity that combine several aspects of diversity such as species evenness, species identity as well as the interactions among the species may be better determinants of the response of the ecosystem to biodiversity. Keywords: biodiversity, ecosystem productivity, evenness, dry acidic grasslands, managed grasslands, species richness
\end{abstract}

\section{Introduction}

In the past decade, the effect of species loss on ecosystem functioning such as primary productivity, nutrient relations, ecosystem stability and vulnerability to invasion, as well as vegetation dynamics has received priority in ecological research (Huston, 1997; Tilman et al., 1997; Hector et al., 1999; Loreau, 2000; Kahmen et al., 2005). In spite of the fact that a large number of experiments have been conducted to investigate this relationship, a common theory was not developed so far (Schmid, 2002; Hector et al., 2007).

Generally, two approaches have been used to study the relationship between species richness and ecosystem functioning; the experimental and the observational approach. In the first approach, plant diversity was artificially manipulated (Symstad and Tilman, 2001), while in the observational approach, plant diversity and composition were not 
manipulated; instead comparative studies were conducted in natural plant communities to relate the differences in diversity to the observed productivity along environmental gradients (Kahmen et al., 2005; Grace et al. 2007).

Using the experimental approach, it was concluded that the productivity of the ecosystem increases asymptotically with increasing diversity (Tilman et al., 1997; Hector et al., 1999). This result has been attributed mainly to niche complementarity and facilitation among species (Hooper, 1998; Loreau and Hector, 2001), as well as to the "sampling effect", i.e. an increased probability of including a highly productive or highly competitive species at the higher diversity levels (Huston et al., 2000).

Experiments based on the observational approach show that biodiversity reaches a peak at intermediate productivity levels, which is described by the "hump-backed" model (Grime, 1973). This model indicates that species richness declines in more productive sites due to higher rates of extinction of less competitive species as a result of higher dominance of strong competitors (Kahmen et al., 2005; Grace et al., 2007). The observational approach studies the effect of species diversity on productivity across environmental gradients, where other factors such as soil fertility, climate, disturbance regime, or herbivory are correlated with the observed diversity and productivity levels (Kahmen et al., 2005). Few experiments have distinguished between environmental and biodiversity effects by employing a multivariate statistical analysis (Kahmen et al., 2005; Grace et al., 2007). Generally, a strong correlation between species richness and productivity was not evident in these experiments. This might be explained by the overwhelming effects of environmental factors which might have masked the diversity effect (Diaz and Cabido, 2001; Schmid, 2002; Hector et al., 2007).

New approaches based on natural vegetations are needed to overcome the above mentioned limitations (Chapin et al., 2000; Loreau et al., 2001; Kahmen et al., 2005). In this kind of approach, biotic and/or abiotic factors should not be correlated with the diversity and productivity levels. In the present study, the relationship between plant diversity and productivity was analyzed at two levels; within-site level (i.e. among plots within a site) in order to minimize the influence of environmental factors, and acrosssite level to investigate this relationship across environmental gradients to be compared with the hump-shaped model. We have chosen two different grasslands, species rich, agriculturally managed grasslands (thereafter managed grasslands) which were managed through cutting and/or aftermath grazing and have 9-17 species $\mathrm{m}^{-2}$, and dry acidic nutrient poor not managed grasslands (thereafter natural grasslands) and have a species richness range of $1-5$ species $0.25 \mathrm{~m}^{-2}$ ).

We studied the effect of two components of biodiversity, species number and evenness, on biomass production (thereafter productivity) in order to test whether different diversity components would have different relationships with productivity. Our hypothesis was that at within-site scale there will be a general positive relationship between diversity and productivity, while this relationship will follow the hump-shaped model when the relationship is investigated across environmental gradients.

\section{Materials and methods}

\section{Study sites}

The study sites were chosen from two different grassland types, agriculturally managed and natural grasslands. Chemical characteristics of the managed grassland soil (0-10 cm depth) were: $\mathrm{pH} 6.2,0.06 \mathrm{mg} \mathrm{P} \mathrm{g}^{-1}$ soil and $0.15 \mathrm{mg} \mathrm{K} \mathrm{g}^{-1}$ soil; while for the 
dry acidic natural grassland were: $\mathrm{pH} 5.3,0.022 \times 10^{-3} \mathrm{NH}^{+} \mathrm{kg}^{-1}$ soil and $1.22 \times 10^{-3} \mathrm{~g}$ $\mathrm{NO}_{3}{ }^{-} \mathrm{kg}^{-1}$ soil. Data from the managed grasslands were collected in 2005, while the data collection from the natural grasslands took place in 2006. Data from these grasslands were analyzed separately to eliminate the confounding effect of management history and inter-annual variation in environmental conditions.

In 2005, seven sites (M1-M7), each measuring $30 \times 30 \mathrm{~m}^{2}$ and differing in plant community composition and productivity level (Table 1) were established in agriculturally managed grasslands near Goettingen, central Germany $\left(51^{\circ} 31^{\prime} \mathrm{N}\right.$, $\left.9^{\circ} 55^{\prime} \mathrm{E}\right)$. The sites had not received any mineral fertilizer application, tillage or resowing for at least the last decade. The management consisted of one or two hay cuts per year with occasional aftermath grazing.

In 2006, another three sites (D1-D3) each measuring $10 \times 10 \mathrm{~m}^{2}$ were chosen from a natural (with no management history) dry acidic nutrient poor grassland area located near Fuerth, southern Germany $\left(49^{\circ} 26^{\prime} \mathrm{N}, 10^{\circ} 50^{\prime} \mathrm{E}\right)$, representing early stages of succession and dominated by two pioneer species: Corynephorus canescens and Rumex acetosella (Table 1).

Table 1. Dominant species, species number and average biomass production of the managed and the natural grasslands

\begin{tabular}{|c|c|c|c|}
\hline Site & Dominant species & $\begin{array}{l}\text { Avg. and range of } \\
\text { species number }\end{array}$ & $\begin{array}{l}\text { Avg. and range of above- } \\
\text { ground biomass (g DM m } \text { m }^{-2}\end{array}$ \\
\hline M1 & $\begin{array}{l}\text { Arrhenatherum elatius } \\
\text { Festuca rubra }\end{array}$ & $\begin{array}{l}9.7 \mathrm{~m}^{-2} \\
(8-13)\end{array}$ & $\begin{array}{c}536 \\
(420-651)\end{array}$ \\
\hline M2 & $\begin{array}{l}\text { Festuca rubra } \\
\text { Agrostis stolonifera }\end{array}$ & $\begin{array}{l}17.9 \mathrm{~m}^{-2} \\
(14-23)\end{array}$ & $\begin{array}{c}576 \\
(377-749)\end{array}$ \\
\hline M3 & $\begin{array}{l}\text { Arrhenatherum elatius } \\
\text { Rhinantus angustifolia }\end{array}$ & $\begin{array}{l}16.6 \mathrm{~m}^{-2} \\
(11-22)\end{array}$ & $\begin{array}{c}409 \\
(284-507)\end{array}$ \\
\hline M4 & $\begin{array}{l}\text { Alepocurus pratensis } \\
\text { Dactylis glomerata }\end{array}$ & $\begin{array}{l}12 \mathrm{~m}^{-2} \\
(6-16)\end{array}$ & $\begin{array}{c}392 \\
(328-506)\end{array}$ \\
\hline M5 & $\begin{array}{l}\text { Elymus repens } \\
\text { Ranunculus repens }\end{array}$ & $\begin{array}{l}11 \mathrm{~m}^{-2} \\
(7-15)\end{array}$ & $\begin{array}{c}562 \\
(415-687)\end{array}$ \\
\hline M6 & $\begin{array}{l}\text { Festuca rubra } \\
\text { Holcus lanatus }\end{array}$ & $\begin{array}{l}10.6 \mathrm{~m}^{-2} \\
(6-16)\end{array}$ & $\begin{array}{c}406 \\
(296-621)\end{array}$ \\
\hline M7 & $\begin{array}{l}\text { Lolium perenne } \\
\text { Trifolium repens }\end{array}$ & $\begin{array}{l}13.4 \mathrm{~m}^{-2} \\
(10-19)\end{array}$ & $\begin{array}{c}445 \\
(303-582)\end{array}$ \\
\hline D1 & $\begin{array}{l}\text { Corynephorus canescens } \\
\text { Rumex acetosella }\end{array}$ & $\begin{array}{c}2.50 .25 \mathrm{~m}^{-2} \\
(1-4)\end{array}$ & $\begin{array}{c}49 \\
(14-154)\end{array}$ \\
\hline $\mathrm{D} 2$ & $\begin{array}{l}\text { Corynephorus canescens } \\
\text { Rumex acetosella }\end{array}$ & $\begin{array}{c}2.00 .25 \mathrm{~m}^{-2} \\
(1-4)\end{array}$ & $\begin{array}{c}61 \\
(9-142)\end{array}$ \\
\hline D3 & $\begin{array}{l}\text { Corynephorus canescens } \\
\text { Rumex acetosella }\end{array}$ & $\begin{array}{c}3.80 .25 \mathrm{~m}^{-2} \\
(2-5)\end{array}$ & $\begin{array}{c}91.2 \\
(41-141)\end{array}$ \\
\hline
\end{tabular}




\section{Data collection}

In 2005, 18 one square meter quadrats were established within each site (M1-M7) and used as the experimental units for analysis of the diversity- productivity relationship. Each site was divided into three blocks, in each block six quadrats were established, the quadrats were fixed systematically along the block (beginning, middle and the end of the block). For each quadrat, all occurring plant species were recorded and the proportion of each species from the total dry weight biomass was visually estimated following a method of percentage ranking (Whalley and Hardy, 2000). Above-ground biomass (used as surrogate for the above-ground productivity) was measured for each quadrat by harvesting all plant material $(>2 \mathrm{~cm})$. The harvest took place when the swards reached the maximum yield (at peak standing crop point). The sampling period lasted from beginning of June to mid July. Before harvesting, the yield was recorded periodically using the rising plate meter method to determine peak standing crop (Correll et al., 2003). This is a nondestructive method which can be used repeatedly on the same plot to estimate the herbage yield. Below-ground biomass (thereafter below-ground productivity) was measured for three sites (because of time and labor limitations): M1, M2 and M3 by taking a soil cylinder $(10 \mathrm{~cm}$ diameter $\mathrm{X}$ $20 \mathrm{~cm}$ depth) at the center of each quadrat. Root samples were then washed with running tap water over a sieve (1 mm mesh size), cleaned manually with forceps and collected on aluminum trays. All harvested plant material was oven dried $\left(103{ }^{\circ} \mathrm{C}\right)$ until constant mass and weighed.

In the natural grassland, 15 quadrats of $0.25 \mathrm{~m}^{2}$ were established randomly at each of the three sites. The same measurements as described for the managed grassland were carried out in these quadrats, except that Braun-Blanquet classes were used to estimate species canopy cover instead of the estimation of dry biomass proportion for each species and that the root biomass for each quadrat was harvested totally (by excavating all root materials in the upper $20 \mathrm{~cm}$ ) rather than taking soil cylinders as done in the managed grassland plots.

\section{Data analysis}

The diversity-productivity relationship was analyzed at two levels; within-site level (data from one site) and across-sites level (data from all sites within each grassland type).

\section{Diversity analysis}

Diversity measures included species richness (S) and species evenness ( $\left.\mathrm{J}^{\prime}\right)$ (Ma, 2005). Species richness was determined as the total number of species present in a quadrat. Species evenness was obtained using the following equation:

$$
\mathrm{J}^{\prime}=\mathrm{D}^{\prime} / \mathrm{D}_{\max }
$$

where $\mathrm{D}_{\max }=\mathrm{S}$

and $\mathrm{D}^{\prime}=1 / \sum\left(\mathrm{P}_{\mathrm{s}}^{2}\right)$, where $\mathrm{P}_{\mathrm{s}}$ is species proportion. 


\section{Statistical analysis}

Least squares simple linear regressions were used to analyze the relationship between plant diversity (species richness and evenness) and productivity (above- and belowground biomass). Assumptions of the regression models were tested by graphical and numerical methods as Q-Q plot and Kolmogorov-Smirnov test for normality of residuals and scatter diagrams of residuals and predicted values for the constancy of variance. Statistical analyses were performed using SPSS version 12.0 (SPSS 2001).

\section{Results}

\section{Within-site level}

In the managed grasslands, the relationship between species richness and aboveground productivity was significant for two sites (M5 and M6) with a negative correlation. Evenness was positively correlated with above-ground productivity for two sites (M1, M2). The relationship between diversity and below-ground productivity was rather weak as only one site $(\mathrm{M} 1)$ showed a significant correlation $\left(\mathrm{R}^{2}=0.23, \mathrm{P}<0.1\right)$ between evenness and below-ground biomass (Table 2). In the natural grasslands, no significant relationship between species richness and evenness and productivity was found.

Table 2. $R^{2}$ of the relationship between plant diversity and productivity in the managed and natural grasslands, within-site level (NS $=$ not significant $+p<0.1 ; * p<0.05 ; * * p<0.01$. $)$

\begin{tabular}{c|c|c|c|c}
\hline \multirow{2}{*}{} & \multicolumn{2}{|c|}{ Above-ground } & \multicolumn{2}{c}{ Below-ground } \\
\cline { 2 - 5 } & Species number & Evenness & Species number & Evennes \\
\hline Managed & $0.00^{\mathrm{ns}}$ & $0.19^{+}$ & $0.0^{\mathrm{ns}}$ & $0.23^{+}$ \\
M1 & $0.07^{\mathrm{ns}}$ & $0.25^{\mathrm{n}}$ & $0.06^{\mathrm{ns}}$ & $0.12^{\mathrm{ns}}$ \\
M2 & $0.00^{\mathrm{ns}}$ & $0.04^{\mathrm{ns}}$ & $0.0^{\mathrm{ns}}$ & $0.0^{\mathrm{ns}}$ \\
M3 & $0.01^{\mathrm{ns}}$ & $0.11^{\mathrm{ns}}$ & - & - \\
M4 & $0.37^{* *}$ & $0.04^{\mathrm{ns}}$ & - & - \\
M6 & $0.19^{+}$ & $0.00^{\mathrm{ns}}$ & - & - \\
M7 & $0.00^{\mathrm{ns}}$ & $0.00^{\mathrm{ns}}$ & - & $0.11^{\mathrm{ns}}$ \\
Natural & $0.05^{\mathrm{ns}}$ & $0.04^{\mathrm{ns}}$ & $0.18^{\mathrm{ns}}$ & $0.04^{\mathrm{ns}}$ \\
D1 & $0.10^{\mathrm{ns}}$ & $0.05^{\mathrm{ns}}$ & $0.10^{\mathrm{ns}}$ & $0.06^{\mathrm{ns}}$ \\
D2 & $0.02^{\mathrm{ns}}$ & $0.11^{\mathrm{ns}}$ & $0.00^{\mathrm{ns}}$ & \\
D3 & \multicolumn{2}{|}{}
\end{tabular}

\section{Across-sites level}

Evenness seems to be more important in explaining the variation in above- and below-ground productivity than species richness. Across all managed sites, productivity increased linearly with increasing evenness $\left(\mathrm{R}^{2}=0.14\right.$ and $0.11, \mathrm{P}<0.001$ and $\mathrm{P}<$ 0.016 for above- and below-ground productivity, respectively). However, there was no significant relationship between species richness and productivity (Fig. 1). 


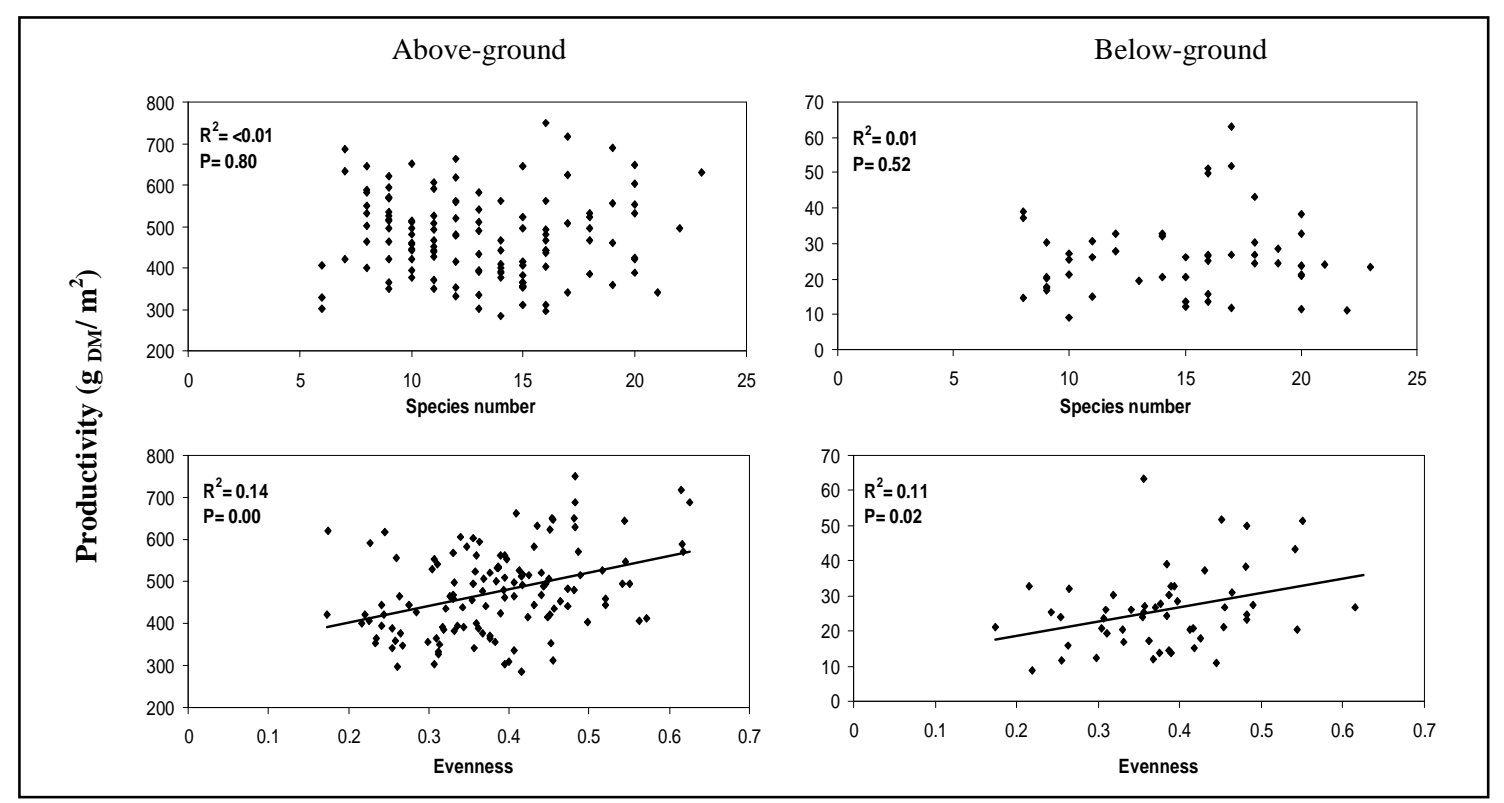

Figure 1. The relationship between diversity (species richness and evenness) and productivity (above-and below-ground) in the managed grasslands across sites

In the natural sites (Fig. 2), productivity (both above- and below-ground) increased linearly with increasing species richness. No such effect was found for the relationship between productivity and evenness.

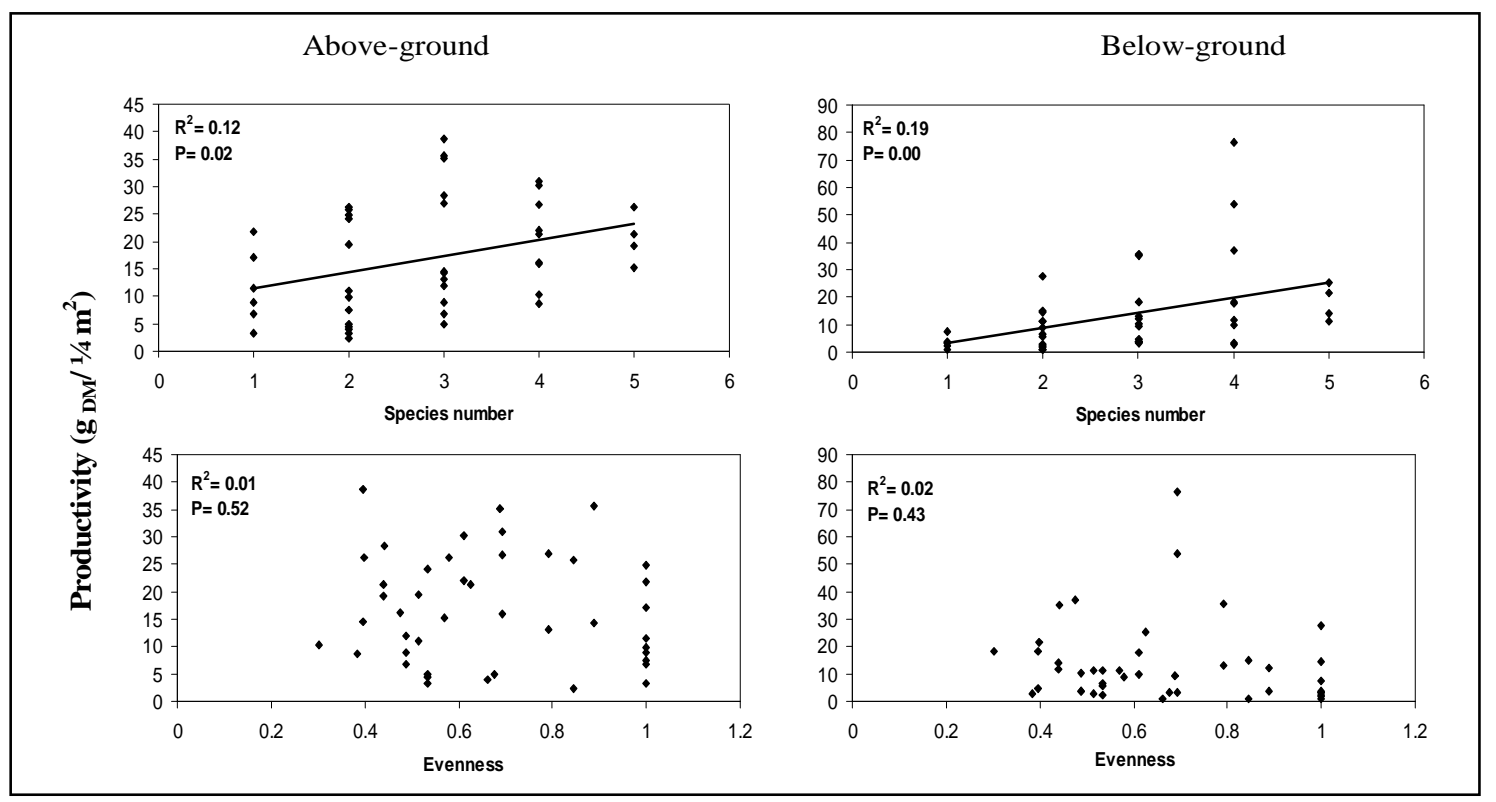

Figure 2. The relationship between plant diversity (species richness and evenness) and productivity (above- and below-ground) of the natural grasslands across sites 


\section{Discussion}

Most of the controversies regarding the diversity-productivity relationship are raised from two points: (i) the effect of various diversity components (species richness, evenness, community composition and functional diversity) on ecosystem processes, and (ii) the inconsistency between results obtained from the experimental and the observational approach (Huston, 1997; Grime, 1997; Diaz and Cabido, 2001; Loreau et al., 2002; Hector et al., 2007). In the present experiment, the relationship between diversity and productivity in the managed grasslands varied according to the diversity measure used (i.e. species richness or evenness). The positive relationship between evenness and productivity at within-site as well as across-sites scale in the managed grasslands indicates that evenness may be more related to ecosystem functions than species richness. It has previously been hypothesized that evenness might be more related to productivity and nutrient cycling of the ecosystems than number of species (Wilsey and Potvin, 2000). Furthermore, ecosystems with evenly distributed species might use resources more efficiently, both spatially and temporally. Compared to evenness, species richness is greatly influenced by sub-ordinate species that have low abundance, while those species would have negligible effects on productivity or other ecosystem functions (Tilman et al., 1997; Spehn et al., 2002; Laird et al., 2003; Kahmen et al., 2005). Previous studies also indicated that species richness showed only weak relationships with productivity (Tilman et al., 1997; Kahmen et al., 2005).

Contrary to the managed sites, none of the natural sites showed a significant relationship between diversity and above-ground productivity at within-site scale. Previous studies (eg. Laird et al., 2003) have shown a significant relationship between diversity and productivity in sites characterized as early successional. Our results could be explained by the fact that the variations in diversity and productivity levels within each site of the dry acidic grassland were too low to produce statistically significant relationship (Table 1).

Overall, our analysis at within-site scale indicates that there is no general relationship between plant diversity and productivity that is consistent for all sites and that the type of the diversity-productivity relationship could be influenced by the existing environmental conditions. Therefore, our results are not in agreement with the results obtained from experimental grasslands where an asymptotic increase in productivity along with increasing species richness was found (Hector et al., 1999).

Our analysis at across-sites level allows comparing our results with the observational approach as both of them investigate the diversity-productivity relationship across environmental gradients. The results obtained from the managed grasslands (Fig. 1) showed a general positive diversity-productivity relationship when the diversity measure was evenness. However, species richness showed no significant relationship with productivity nor did it behave according to the hypothesized hump-backed model (Grime, 1973). The explanation for this might be that obtaining the hump-shaped relationship requires the extreme environmental conditions to be included into the surveyed plots (stress factors at one end and conditions that favor high productivity at the other end). A lack of these extreme conditions which cause low and high productivity levels would produce a diversity productivity relationship that is located at the center of the hump-shaped curve (Fig. 1). Another explanation could also be that the complementarity between species does not increase with increasing number of species 
(redundancy) in the relatively species rich managed grasslands (Laird et al., 2003). This is confirmed by the positive species richness-productivity relationship in the natural grasslands (Fig. 2), which is characterized by a lower number of species compared to managed grasslands.

Interestingly, our results from the natural grasslands at across-site scale are in agreement with the results obtained from the experimental approach (e.g. Naeem et al., 1996; Hector et al., 1999). In those experiments, the positive relationship has been mainly attributed to niche complementarity and sampling effect, where it has been argued that the diversity effect could also be driven by the plots with low species richness (Kahmen et al., 2005). In our natural grasslands, it seems that those factors might also play an important role in producing such positive relationships in early successional sites because of the low species number and of ecological processes which have not yet reached equilibrium (Wardle, 1999; Laird et al., 2003).

Our results indicate that the relationship between diversity and productivity is different for the managed, species rich, productive grasslands in one hand and the nutrient poor, low productive natural grasslands in another hand. Compared to the managed grasslands, natural dry acidic grasslands are characterized by lower fertility and lower water availability during the growing season due to the low water holding capacity of the sandy soils. Diversity (species richness) effects might be stronger in low productive nutrient and species poor grasslands than in the agriculturally managed grasslands, where plant species could be functionally more redundant. This might explain why increasing species number was accompanied by higher productivity in the natural, but not in the managed grasslands, at across-site scale. On the other hand, it may also be that there is no causal relationship between the higher biomass values and the higher species richness values in our natural grasslands and that the observed positive relationship might just be due to the fact that the higher species numbers in the more productive plots results from a better species establishment in these plots after disturbance (Laird et al., 2003).

\section{Conclusions}

A reconciliation of the results obtained from the experimental and the observational approaches might enable us to understand the factors that regulate the relationship between biodiversity and ecosystem functioning as well as expand our current knowledge of conservation and ecosystem processes in natural ecosystems. We think that a single general diversity-productivity relationship does not properly characterize the natural vegetations, thus biotic and/or abiotic factors might affect this relationship significantly. We suggest that future experiments should be continued in natural vegetations and that the investigated sites should be pre-classified according to their differences in ecological, compositional, or environmental characteristics. There is a need to include environmental factors in the future studies (rather than to control them) in order to investigate their effects on the biodiversity-productivity relationship.

Acknowledgements. We are grateful to Dr. T. Steinlein for his assistance and support, and Prof. Dr. R.J. Ryel for critical reading of an earlier version of the manuscript, and S. Kesting for his invaluable help in plant identification. We also thank M. Seither and B. Hohlmann for their help in the field. During the study period, T. A. was funded by an unrestricted educational grant provided from the German Academic Exchange Program (DAAD). 


\section{REFERENCES}

[1] Chapin, F.S. et al. (2000: Consequences of changing biodiversity. - Nature 405: 234-242.

[2] Correll, O. et al. (2003): Studying spatial and temporal dynamics of sward structure at low stocking densities: the use of an extended rising-plate-meter method. - Grass Forage Sci. 58: 450-454.

[3] Diaz, S., Cabido, M. (2001): Vive la difference: plant functional diversity matters to ecosystem processes. - Trends Ecol. Evol. 16: 646-655.

[4] Grace, J.B. et al. (2007): Does species diversity limit productivity in natural grassland communities? - Ecol. Lett. 10: 680-689.

[5] Grime, J.P. (1973): Competitive exclusion in herbaceous vegetation. - Nature 242: 344347.

[6] Grime, J.P. (1997): Biodiversity and ecosystem function: the debate deepens. - Science 277: $1260-1261$.

[7] Hector, A. et al. (1999): Plant diversity and productivity experiments in European grasslands. - Science 28: 1123-1127.

[8] Hector, A. et al. (2007): Biodiversity and ecosystem functioning: reconciling the results of experimental and observational studies. - Funct. Ecol. 21: 998-1002.

[9] Hooper, D.U. (1998): The role of complementarity and composition in ecosystem responses to variation in plant diversity. - Ecol. 79: 704-719.

[10] Huston, M.A. (1997): Hidden treatments in ecological experiments: re-evaluating the ecosystem function of biodiversity. - Oecologia 110: 449-460.

[11] Huston, M.A. et al. (2005): Effects of plant diversity, community composition and environmental parameters on productivity in montane European grasslands. - Oecologia 142: 606-615.

[12] Laird, R.A. et al. (2003): Species evenness, not richness, has a consistent relationship with productivity in old-field vegetation. - Community Ecol. 4: 21-28.

[13] Loreau, M., Hector, A. (2001): Partitioning selection and complementarity in diversity experiments. - Nature 412: 72-76.

[14] Loreau, M. (2000): Biodiversity and ecosystem functioning: recent theoretical advances. - Oikos 91: 3-17.

[15] Loreau, M. et al. (2001): Biodiversity and ecosystem functioning: current knowledge and future challenges. - Science 294: 804-808.

[16] Loreau, M. et al. (2002): Biodiversity and Ecosystem Functioning: Synthesis and Perspectives. - Oxford University Press, Oxford.

[17] Ma, M. (2005): Species richness vs evenness: independent relationship and different responses to edaphic factors. - Oikos 111: 192-198.

[18] Naeem, S. et al. (1996): Biodiversity and plant productivity in a model assemblage of plant species. - Oikos 76: 259-264.

[19] Schmid, B. (2002): The species richness-productivity controversy. - Trends Ecol. Evol. 17: 113-114.

[20] Spehn, E.M. et al. (2002): The role of legumes as a component of biodiversity in a crossEuropean study of grassland biomass nitrogen. - Oikos 98: 205-218.

[21] SPSS Inc. (2001): SPSS Base 11.0 user's guide. - SPSS, Chicago.

[22] Symstad, A.J., Tilman, D. (2001): Diversity loss, recruitment limitation, and ecosystem functioning: lessons learned from a removal experiment. - Oikos 92: 424-435.

[23] Tilman, D. et al. (1997): Plant diversity and ecosystem productivity: Theoretical considerations. - Proc. Natl. Acad. Sci. USA 94: 1857-1861.

[24] Wardle, D.A. (1999): Is "sampling effect" a problem for experiments investigating biodiversity ecosystem function relationship? - Oikos 87: 403-407. 
[25] Whalley, R.D.B., Hardy, M.B. (2000): Measuring botanical composition of grasslands. In: 't Mannetje, L., Jones, R.M. (ed.) Field and Laboratory Methods for Grassland and Animal Production Research, Wallingford, UK, CAB International, pp. 67-102.

[26] Wilsey, B.J., Potvin, C. (2000): Biodiversity and ecosystem functioning: importance of species evenness in an old field. - Ecol. 81: 887-892. 